\title{
Scar tissue prevention and revision - introduction to a special issue
}

\author{
Jérôme Laloze ${ }^{1,2}$, Alexis Desmoulière ${ }^{1}$ \\ ${ }^{1}$ Faculties of Medicine and Pharmacy, Myelin Maintenance and Peripheral Neuropathies (EA 6309), University of Limoges, \\ Limoges F-87000, France. \\ ${ }^{2}$ Department of Maxillo-Facial and Reconstructive Surgery and Stomatology, University Hospital Dupuytren, Limoges F-87000, \\ France.
}

Correspondence to: Prof. Alexis Desmoulière, Faculties of Medicine and Pharmacy, Myelin Maintenance and Peripheral Neuropathies (EA 6309), University of Limoges, Limoges F-87000, France. E-mail: alexis.desmouliere@unilim.fr

How to cite this article: Laloze J, Desmoulière A. Scar tissue prevention and revision - introduction to a special issue. Plast Aesthet Res 2021;8:25. https://dx.doi.org/10.20517/2347-9264.2021.28

Received: 25 Mar 2021 Accepted: 8 Apr 2021 Published: 8 May 2021

Academic Editor: Raúl González-García Copy Editor: Xi-Jun Chen Production Editor: Xi-Jun Chen

The wound healing process is complex and, despite many advances in both fundamental research and plastic surgery, the mechanisms underlying tissue repair remain poorly understood.

After surgery or trauma, the plastic surgeon needs to use all the means at his or her disposal to both obtain a stable scar and achieve the most aesthetic result. However, before this can be achieved, there is a long and sometimes difficult phase, lasting up to 18-24 months. Moreover, the surgeon will sometimes have to deal with complications related to either poor or excessive (defective or pathological) scarring. These complications, which are both physiological and psychological, particularly in aesthetic plastic surgery, are difficult to treat since there is at present no consensus, and they thus continue to represent a significant public health issue. Therefore, it is important to understand all of the closely interwoven aspects of healing, including structural and surgical aspects, for both prevention and revision of scarring.

Prevention of scarring involves good surgical technique, adaptation to the individual patient and the use of creams, compression and physiotherapy. Revision involves a thorough knowledge of the different stages of healing and the specific dressings related to these stages. In any case, close patient support is still necessary. 
With this special issue on "scar tissue prevention and revision", we aim to summarize the state of the art of both translational and clinical research and present current trends and future prospects for the management of wound healing.

We are fortunate that for this special issue renowned authors have agreed to share their experiences on the subject of pathological scarring.

Scar repair in adult skin has been studied in depth over many years. The healing process is very complex, since many cells and trophic factors are involved, which interact with each other. Healing also involves a well-defined sequence of phases ${ }^{[1]}$, of which inflammation is the first, and possibly most important, phase when considering future pathological scar formation.

For this reason, we are greatly interested in the review of the literature by Wilgus ${ }^{[2]}$, which reminds us of the prominent role of inflammation in the scarring process. Several reviews have already highlighted a link between the occurrence of pathological scarring and excessive inflammation ${ }^{[3]}$. Indeed, in scar tissue, higher concentrations of mediators such as interleukins (IL)-6 and IL-8, which are both pro-inflammatory cytokines $^{[4]}$, and increased numbers of pro-inflammatory cells (mast cells and macrophages) ${ }^{[5]}$ are present. These molecular and cellular findings are of obvious clinical interest. Thus, local or systemic therapies that can reduce inflammation are used in this goal. Corticosteroids, for example, have long been used to treat hypertrophic scars or keloid scars by intra-lesional injection $s^{[6,7]}$, with their value having been demonstrated in several studies. Other treatments such as nonsteroidal anti-inflammatory drugs ${ }^{[8,9]}$, toll like receptor-4 inhibitors ${ }^{[10]}$, CXCR4 antagonists ${ }^{[11]}$, pirfenidone ${ }^{[12]}$, epigallocatechin-3-gallate ${ }^{[13]}$ or fibromodulin $^{[14]}$ are also currently being studied. Even though results on these latter therapies are conflicting, Wilgus outlined the treatment arsenal available to the clinician who is sometimes lost when faced with the distress caused by these scars.

Wilgus also discussed two phenomena that are well known by surgeons and nurses when dealing with scars. It is important to reduce the tension in the scar ${ }^{[15]}$ and maintain a moist environment ${ }^{[16]}$ in order to reduce scar inflammation and thus reduce the risk of scar tissue formation. For example, focal adhesion kinase (FAK) signaling pathways, which control mechanical signaling in fibroblasts, are linked to an increased inflammatory response ${ }^{[17]}$. Future treatments could be used to target and control these FAK signaling pathways. Very recently, Fu et al. ${ }^{[18]}$ published an interesting review on the phenomenon of mechanotransduction in wound healing, outlining the principles and pathways involved. In it, they reviewed the numerous clinical tools that are based on this pathway and can be used to manage the complex or large wounds that would definitely lead to major scar tissue. Clinicians can easily identify these tools: the expanders used in the aftermath of burns or giant nevi ${ }^{[19]}$, the External Vacuum Expander $\left(\mathrm{EVE}^{\oplus}\right)$ or $\mathrm{BRAVA}^{\oplus}$ system in breast augmentation ${ }^{[20]}$, negative pressure therapy for complex and deep wounds ${ }^{[21]}, \mathrm{Z}$ plasty $^{[22]}$, etc. Fu et al. ${ }^{[18]}$ thus provided a description of "mechanotransduction to mechanotherapy".

Scar tissue can occur after traumatic injuries (burns, etc.) as well as after surgery ${ }^{[23]}$. However, Mirastschijski et al. ${ }^{[2]}$ pointed out that not all regions are equal in terms of healing. Indeed, the skin of the genital region, thanks to the embryological origins of its fibroblasts and its hormonal environment, has very specific healing properties. Pathological scars are rare in this body region.

Conversely, after a burn, the frequency of pathological scars such as hypertrophic scars, keloids or retractile scars can be as high as $70 \%^{[24,25]}$ [Figure 1]. Scar tissue shows different properties to normal skin in terms of reduced tensile strength, reduced laxity and being more rigid to palpation. It can thus cause physical 


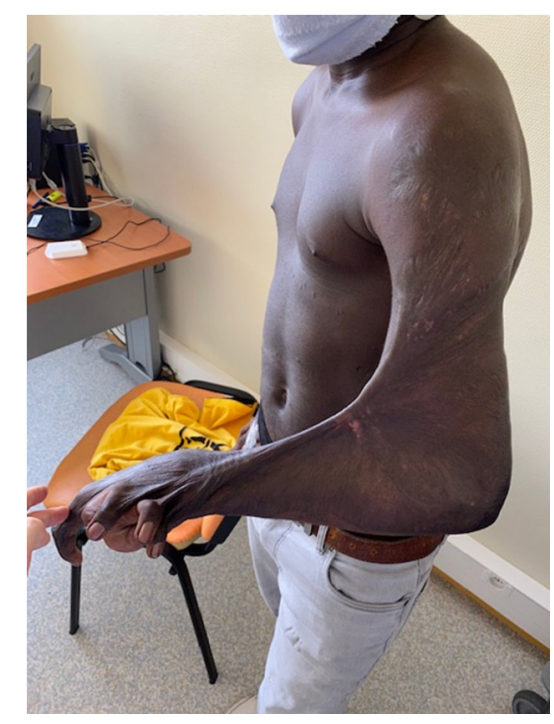

Figure 1. Retractile scar after burn injuries during childhood, involving the elbow, wrist and fingers.

suffering (pruritus, pain, erythema, etc.) as well as psychological suffering ${ }^{[2,27]}$. It is therefore essential to optimize their management. The paper by Wong et al. ${ }^{[28]}$ presents the current therapeutic possibilities for the prevention of these scars (compression therapy, silicone plat and massage therapy) and their treatment (surgical revision, laser therapy, corticosteroids, etc.). Interestingly, they also provided an overview of new approaches for the treatment of hypertrophic scars after burns. These include, for example, therapies regulating transforming growth factor- $\beta$, such as Juvista ${ }^{[29]}$ or Juvidex ${ }^{[30]}$; Prevascar (a recombinant human IL-10 product), which can decrease the action of IL- 6 and IL- $8^{[30,31]}$; mesenchymal stem cells or epithelial cells $^{[32]}$; and finally new polymer-stress shielding devices ${ }^{[1,3,3]}$ that act via reducing the mechanical stress in scar tissue. This last point is also addressed by the article of Lemperle ${ }^{[34]}$ on the importance of tensional forces in the skin in surgical scar placement.

Indeed, regarding the phenomena of mechanical tension, another means exists that has been well known by plastic surgeons for more than a century (since 1861) ${ }^{[35]}$ to reduce the risk of hypertrophic scarring after surgery, which is to position (as much as possible) future surgical scars along the lines of least skin tension, i.e., according to Langer's lines. Lemperle ${ }^{[34]}$ emphasized the importance of these planned incisions in a richly illustrated and exhaustive article, which covers each part of the body separately. Thus, care must be taken to observe the lines of least skin tension, which are themselves perpendicular to the orientation of stretch marks ${ }^{[36]}$.

Finally, a risk factor that is comparatively unknown to the scientific community, and which could also contribute to causing pathological scars, is the level of stress. Yang et al. ${ }^{\left[{ }^{37]}\right.}$ studied this phenomenon and sought to understand how emotion could play a role in the appearance of such scars or encourage their recurrence (which remains very high in keloid scars, ranging 9\%-100\%). Indeed, they identified three possible pathways involved: stress hormones (norepinephrine and epinephrine) increase the level of IL- 6 by activating-adrenergic receptors, increase the growth and proliferation of fibroblasts in scar tissue by activating-adrenergic receptors, and dysregulate the immune system by promoting an inflammatory environment. 
In this special issue, we trust that both clinicians and researchers will find accurate and up to date answers regarding the prevention of scar tissue and scar revision.

\section{DECLARATIONS}

\section{Authors' contributions}

Writing and drafting of the manuscript, providing of the illustration: Laloze J

Advice and intellectual support, correction and proofreading of the manuscript: Desmoulière A

\section{Available of data and materials}

Not applicable.

\section{Financial support and sponsorship}

None.

\section{Conflicts of interest}

Both authors declared that there are no conflicts of interest.

\section{Ethical approval and consent to participate}

All patients sign a consent form at the time of admission that they are informed that any photos may be used for scientific purposes and publications.

\section{Consent for publications}

Not applicable.

\section{Copyright}

(c) The author(s) 2021.

\section{REFERENCES}

1. Gurtner GC, Werner S, Barrandon Y, Longaker MT. Wound repair and regeneration. Nature 2008;453:314-21. DOI PubMed

2. Wilgus TA. Inflammation as an orchestrator of cutaneous scar formation: a review of the literature. Plast Aesthet Res 2020;7:54. DOI PubMed PMC

3. Qian LW, Fourcaudot AB, Yamane K, You T, Chan RK, Leung KP. Exacerbated and prolonged inflammation impairs wound healing and increases scarring. Wound Repair Regen 2016;24:26-34. DOI PubMed

4. Zhang Q, Yamaza T, Kelly AP, et al. Tumor-like stem cells derived from human keloid are governed by the inflammatory niche driven by IL-17/IL-6 axis. PLoS One 2009;4:e7798. DOI PubMed PMC

5. Dong X, Zhang C, Ma S, Wen H. Mast cell chymase in keloid induces profibrotic response via transforming growth factor- $\beta 1 /$ Smad activation in keloid fibroblasts. Int J Clin Exp Pathol 2014;7:3596-607. PubMed PMC

6. Amini-Nik S, Yousuf Y, Jeschke MG. Scar management in burn injuries using drug delivery and molecular signaling: Current treatments and future directions. Adv Drug Deliv Rev 2018;123:135-54. DOI PubMed PMC

7. Roques C, Téot L. The use of corticosteroids to treat keloids: a review. Int J Low Extrem Wounds 2008;7:137-45. DOI PubMed

8. Yuan Z, Zhao J, Chen Y, Yang Z, Cui W, Zheng Q. Regulating inflammation using acid-responsive electrospun fibrous scaffolds for skin scarless healing. Mediators Inflamm 2014;2014:858045. DOI PubMed PMC

9. Rahmani-Neishaboor E, Jallili R, Hartwell R, Leung V, Carr N, Ghahary A. Topical application of a film-forming emulgel dressing that controls the release of stratifin and acetylsalicylic acid and improves/prevents hypertrophic scarring. Wound Repair Regen 2013;21:55-65. DOI PubMed

10. Wang J, Hori K, Ding J, et al. Toll-like receptors expressed by dermal fibroblasts contribute to hypertrophic scarring. J Cell Physiol 2011;226:1265-73. DOI PubMed

11. Ding J, Hori K, Zhang R, et al. Stromal cell-derived factor 1 (SDF-1) and its receptor CXCR4 in the formation of postburn hypertrophic scar (HTS). Wound Repair Regen 2011;19:568-78. DOI PubMed

12. Dorati R, Medina JL, DeLuca PP, Leung KP. Development of a Topical 48-H Release Formulation as an Anti-scarring Treatment for Deep Partial-Thickness Burns. AAPS PharmSci Tech 2018;19:2264-75. DOI PubMed

13. Ud-Din S, Foden P, Mazhari M, et al. A double-blind, randomized trial shows the role of zonal priming and direct topical application of epigallocatechin-3-gallate in the modulation of cutaneous scarring in human skin. J Invest Dermatol 2019;139:1680-90.e16. DOI PubMed 
14. Pang X, Dong N, Zheng Z. Small leucine-rich proteoglycans in skin wound healing. Front Pharmacol 2019;10:1649. DOI PubMed PMC

15. Gurtner GC, Dauskardt RH, Wong VW, et al. Improving cutaneous scar formation by controlling the mechanical environment: large animal and phase I studies. Ann Surg 2011;254:217-25. DOI PubMed

16. Breuing K, Eriksson E, Liu P, Miller DR. Healing of partial thickness porcine skin wounds in a liquid environment. J Surg Res 1992;52:50-8. DOI PubMed

17. Dohi T, Padmanabhan J, Akaishi S, et al. The interplay of mechanical stress, strain, and stiffness at the keloid periphery correlates with increased caveolin-1/ROCK signaling and scar progression. Plast Reconstr Surg 2019;144:58e-67e. DOI PubMed

18. Fu S, Panayi A, Fan J, et al. Mechanotransduction in wound healing: From the cellular and molecular level to the clinic. Adv Skin Wound Care 2021;34:67-74. DOI PubMed

19. Neumann CG. The expansion of an area of skin by progressive distention of a subcutaneous balloon; use of the method for securing skin for subtotal reconstruction of the ear. Plast Reconstr Surg 1957;19:124-30. DOI PubMed

20. Oranges CM, Striebel J, Tremp M, Madduri S, Kalbermatten DF, Schaefer DJ. The Impact of Recipient Site External Expansion in Fat Grafting Surgical Outcomes. Plast Reconstr Surg Glob Open 2018;6:e1649. DOI PubMed PMC

21. Panayi AC, Leavitt T, Orgill DP. Evidence based review of negative pressure wound therapy. J Dermatol 2017;6:1-16. DOI

22. Huang C, Ono S, Hyakusoku H, Ogawa R. Small-wave incision method for linear hypertrophic scar reconstruction: a parallel-group randomized controlled study. Aesthetic Plast Surg 2012;36:387-95. DOI PubMed

23. Aarabi S, Longaker MT, Gurtner GC. Hypertrophic scar formation following burns and trauma: new approaches to treatment. PLoS Med 2007;4:e234. DOI PubMed PMC

24. Mirastschijski U, Jiang D, Rinkevich Y, Karim R, Sorg H. Wound repair and scarring of genital skin. Plast Aesthet Res 2020;7:70. DOI

25. Lawrence JW, Mason ST, Schomer K, Klein MB. Epidemiology and impact of scarring after burn injury: a systematic review of the literature. J Burn Care Res 2012;33:136-46. DOI PubMed

26. Gauglitz GG, Korting HC, Pavicic T, Ruzicka T, Jeschke MG. Hypertrophic scarring and keloids: pathomechanisms and current and emerging treatment strategies. Mol Med 2011;17:113-25. DOI PubMed PMC

27. Sainsbury DC. Body image and facial burns. Adv Skin Wound Care 2009;22:39-44; quiz 45. DOI PubMed

28. Wong J, Lin W, Ding J, Tredget EE. Prevention and management of scarring after thermal injury. Plast Aesthet Res 2021;8:9. DOI

29. So K, McGrouther DA, Bush JA, et al. Avotermin for scar improvement following scar revision surgery: a randomized, double-blind, within-patient, placebo-controlled, phase II clinical trial. Plast Reconstr Surg 2011;128:163-72. DOI PubMed

30. Meier K, Nanney LB. Emerging new drugs for wound repair. Expert Opin Emerg Drugs 2006;11:23-37. DOI PubMed

31. Sun ZL, Feng Y, Zou ML, et al. Emerging Role of IL-10 in Hypertrophic Scars. Front Med (Lausanne) 2020;7:438. DOI PubMed PMC

32. Li Z, Maitz P. Cell therapy for severe burn wound healing. Burns Trauma 2018;6:13. DOI PubMed PMC

33. Januszyk M, Wong VW, Bhatt KA, et al. Mechanical offloading of incisional wounds is associated with transcriptional downregulation of inflammatory pathways in a large animal model. Organogenesis 2014;10:186-93. DOI PubMed PMC

34. Lemperle G. Prevention of hyper- and hypotrophic scars through surgical incisions in the direction of the "main folding lines" of the skin. Plast Aesthet Res 2020;7:40. DOI

35. Langer K. On the anatomy and physiology of the skin. Br J Plast Surg 1978;31:277-8. DOI PubMed

36. Kraissl CJ, Conway H. Excision of small tumors of the skin of the face with special reference to the wrinkle lines. Surgery 1949;25:592-600. PubMed

37. Yang Y, Wu X, Liu W. Psychological stress enhances keloid development via stress hormone-induced abnormal cytokine profiles and inflammatory responses. Plast Aesthet Res 2020;7:34. DOI 